\title{
Too Close to be Similar: Product and Price Competition in Retail Gasoline Markets
}

\author{
March 2008
}

\begin{abstract}
We examine how product and pricing decisions of retail gasoline stations depend on local market demographics and the degree of competitive intensity in the market. We are able to shed light on the observed empirical phenomenon that proximate gasoline stations price very similarly in some markets, but very differently in other markets. Our analysis of product design and price competition between firms integrates two critical dimensions of heterogeneity across consumers: Consumers differ in their locations and in their travel costs, as in models of horizontal differentiation. They also differ in their relative preference or valuations for product quality dimensions, in terms of the offered station services (such as pay-at-pump, number of service bays or other added services), as in models of vertical differentiation. We find that the degree of local competitive intensity and the dispersion in consumer incomes are sufficient to explain variations in the product and pricing choices of competing firms. Closely located retailers who face sufficient income dispersion across consumers in a local market may differentiate on product design and pricing strategies. In contrast, retailers that are farther apart from each other may adopt similar product design and pricing strategies if the market is relatively homogeneous on income. Using empirical survey data on prices and station characteristics gathered across 724 gasoline stations in the St. Louis metropolitan area, and employing a multivariate logit model that predicts the joint probability of stations within a local market differentiating on product design and pricing strategies as a function of market demographics and local competitive intensity, we find strong support for the central implications of the theory.
\end{abstract}

Keywords: Vertical Differentiation, Horizontal Differentiation, Product Competition, Price Competition, Spatial Models, Multivariate Logit, Retail Gasoline Markets. 


\section{Introduction}

In many markets, firms compete not only on price, but also in the design of their products. This paper examines the competitive product design and pricing decisions of firms in retail gasoline markets. We study the following two questions: (1) How do market demographics drive product and pricing decisions of competing gasoline stations? and (2) How does the degree of local competition drive the product and pricing decisions of competing gasoline stations?

While gasoline stations sell a frequently purchased homogeneous product, their product design decision involves the offering of service characteristics such as number of pumping bays, availability of pay-at-pump, car wash facility, attendant pumping (i.e., full service) etc. at the retail location. The price of gasoline at a station is posted and easily observed by competing stations as well as by consumers in the neighborhood. Our interest in this study is to understand how product design and pricing decisions at competing stations within a local retail market respond to the local demographic characteristics (such as income), and the intensity of competition (such as the number of competing firms within the market). There exists some empirical evidence showing that stations in close geographic proximity show significant price variation (Png and Reitman 1994). However, there also exists empirical evidence in favor of modest price variation among closely located firms (Slade 1992). We investigate why gasoline retailers engage in similar pricing decisions in some cases, but not in others. In doing this, we also show that the firms' product design choices are simultaneously driven by the same demographic and competitive factors and that also drive their pricing choices.

We present a model of market competition that explains product and pricing decisions as a function of local market demographics and the proximity of retailers (that serves as a proxy for local competitive intensity) in the market. We test the theory using empirical data on product design and pricing choices of stations in various mutually exclusive, local markets. The paper examines the interplay of product design and pricing choices of competing firms as it relates to two distinct types of consumer heterogeneity characteristics: differences across consumers in their locational preferences (horizontal heterogeneity) and differences across consumers in their preferences for product quality (vertical heterogeneity). We highlight three general features that affect competition in retail gasoline markets. First, consumers differ in their locations and have costs of travel between retailers who are differentiated by their location, as in models 
of horizontal or locational differentiation (e.g., Hotelling 1929, D'Aspermont, Gabszewicz and Thisse 1979). Second, consumers also differ in their relative preference or valuation for product quality, as in models of vertical differentiation (e.g., Mussa and Rosen 1978, Shaked and Sutton 1982, Moorthy 1988). Third, we assume that there exists a positive relationship in retail markets between the travel/time cost incurred by a consumer and the consumer's valuation for service quality. The correlation implies that more affluent consumers, who have higher opportunity costs of time, incur a higher cost from travel, while also having a higher valuation for product quality.

The analysis identifies the market conditions under which competing retailers would use differentiated versus undifferentiated product and pricing strategies. Competing stations in markets with a higher variation in income (for a given level of competitive intensity) will differentiate more in their product design and pricing choices, while stations in local markets with higher travel costs, and, therefore, lower competitive intensity (for a given level of local income variation), will differentiate less in their product design and pricing choices. In other words, our model reconciles the previous empirical findings about whether closely located stations will price similarly or differently from each other. Our model predicts that among closely located stations, similar strategies will be observed if they are in markets with little dispersion in incomes, while different strategies will be observed in markets with high dispersion in incomes.

The empirical analysis uses survey data gathered from the retail gasoline market in the Saint Louis metropolitan area. The dataset covers 724 gasoline stations, and includes stationlevel cross-sectional information on price as well as station characteristics (such as number of pumping bays, availability of pay-at-pump, car wash facility, attendant pumping, convenience store, service station facility etc.). The geographic location of each station is coded in Cartesian coordinates on a map of Saint Louis and also associated with the relevant census tract. The dataset also includes demographic information about per-capita income, population and other market characteristics. In the empirical analysis, we operationalize the product design decision of a firm using two indicator variables, each tracking a different ancillary service that can be available at the station. We define mutually exclusive census tracts as local markets, and treat each market as the unit of observation in the empirical analysis. This results in 186 local markets with two or more stations. For each market defined thus, we compute three outcome measures: 
(1) the standard deviation of two product design measures across all firms in the market, and (2) the standard deviation of pricing choices across all firms in the market. We then compute the following explanatory variables for each market: (1) standard deviation of the incomes in the local market, and (2) number of firms in the local market divided by its geographic land area to capture local competitive intensity. A multivariate logit model is estimated to explain the joint probability of observing the three outcome variables (i.e., two product design outcomes, plus one pricing outcome) in a local market as a function of the two explanatory variables, after controlling for extraneous drivers of the three outcomes (as will be explained later). The econometric model permits the three outcome variables to be correlated with each other. We validate both of the key predictions of our theory in the empirical analysis, i.e., (1) competing stations in local markets with a higher variation in income (for a given level of competitive intensity) show a larger spread in their product design and pricing choices, and (2) stations in local markets with higher competitive intensity (for a given level of local income variation) show a larger spread in their product design and pricing choices.

\section{$1.1 \quad$ Related Research}

Much of the existing empirical literature has studied either the pricing or the product decisions of firms in competitive markets. For example, Davis (2005) studies the effects of local market structure on prices charged at movie theaters, by running a regression of each firm's price on the number of rival firms present in the market. Draganska and Jain (2006) study how competitive firms should price multiple variants within their existing product lines which are taken to be

fixed. Slade (1986) estimates geographic boundaries for retail gasoline markets, using Granger causality tests to estimate whether temporal price movements in one region of the US have repercussions in another. Pinkse, Slade and Brett (2002) present an empirical technique to discriminate between local and global price rivalry between retail gasoline firms using semiparametric methods to estimate the matrix of price reaction functions of firms. However, all these papers above do not analyze the product choices that firms might make in response to the market characteristics. Furthermore, none of these studies tests the equilibrium predictions of firm competition at the market-level. Mazzeo (2002) estimates product choice decisions of firms in the hotel industry, while Seim (2004) models local market entry decisions of video 
retailers. However, in these studies pricing decisions are not studied. Chan, Padmanabhan and Seetharaman (2007) estimate an econometric model of location and pricing decisions of gasoline stations in the Singapore market, but this paper is focused on the planner's problem rather than on the outcome of equilibrium competition between firms. To summarize, therefore, an empirical test of simultaneous product design and pricing decisions of firms in response to market competition (as in this paper) is missing in the literature.

Anderson, de Palma and Thisse (1996) provide a review of the analytical literature on product and price competition between firms. However, there is little work on the joint consideration of vertical and horizontal differentiation and its implication for firm strategies. The paper that is closest to ours, in this regard, is one by Neven and Thisse (1990), which considers how the location choices of firms are related to quality differentiation. ${ }^{1}$ Our paper, however, considers the effect of the correlation between the location and quality preferences of the consumers on the product and price choices of firms. Our empirical application pertains to retail gasoline markets.

The remainder of the paper is organized as follows. Section 2 develops our theoretical model and derives testable predictions. Section 3 presents the empirical analysis, and section 4 concludes.

\section{Model of Product and Price Competition}

Consider two gasoline retailers, indexed by $j=1,2$, who compete in a market by selling products of quality level $q_{j}$ and price $p_{j}$. While the price $p_{j}$ refers to the price of the basic good - gasoline - at the gasoline station, the quality level $q_{j}$ refers to the quality of the available services such as pay-at-pump, number of service bays etc. at the station (for example, a station with a larger number of ancillary services can be thought of as a higher-quality station). The cost of providing quality is assumed to be increasing and strictly convex in quality, with the functional form $c\left(q_{j}\right)=\frac{q_{j}^{2}}{2}$. Both firms are assumed to have a constant marginal cost of production, which is set to zero without any loss of generality. The two firms are assumed to be at the two ends of a line segment of unit length.

\footnotetext{
${ }^{1}$ Some other papers which model the joint consideration of vertical and horizontal differentiation are Rochet and Stole (2002), Desai (2001) and Schmidt-Mohr and Villas-Boas (2007) in the context of product line competition, and Iyer (1998) in the context of quality screening by a manufacturer of competing retailers in a market.
} 
We assume a market of unit size, whose consumers are uniformly distributed on the line segment. The extent of horizontal heterogeneity in the market is captured by this uniform distribution of consumers on the line. Further, we assume that the consumers are of two types $(i=l, h)$ (of equal size) when it comes to their valuation (or preference) for product quality. $^{2}$ Specifically, let $\theta_{l}$ and $\theta_{h}=v \theta_{l}(v \in(1, \infty))$ denote the valuations of the two segments. ${ }^{3}$ Therefore, the extent of vertical heterogeneity in the market is represented by the discrete distribution of two consumer types (where $v$ is a measure of the spread of the discrete distribution). We assume consumers' locations to be independent of their valuations for product quality, i.e., consumers of both types $(i=l, h)$ are uniformly distributed on the Hotelling line.

Consumers incur travel costs in traveling from their locations to either retailer. A consumer of type $\theta_{i}$ is assumed to incur a travel cost of $t \theta_{i}$ per unit distance, where $t \in[0, \infty)$. For example, consumer $i$, who is of type $\theta_{i}$ and at a distance of $x_{j i}$ from retailer $j$, will incur a travel cost of $t \theta_{i} x_{j i}$ in traveling to retailer $j$. In this sense, $\theta_{i}$ simultaneously determines both the consumer's valuation for quality, as well as the consumer's per-unit travel cost, therefore, implying that a consumer with a higher valuation for quality will also have a higher per-unit travel cost. This can be understood by thinking of $\theta_{i}$ as related to the consumer's income. Higher-income consumers are likely to have not only higher costs of time (and, hence, higher travel cost per unit of distance), but also higher valuations for product quality, compared to lower-income consumers. ${ }^{4}$ The parameter $t$ (which is common across consumers) can be understood as representing the extent of locational differentiation between the two retailers. Specifically, larger values of $t$ imply higher locational differentiation and a lower competitive intensity than smaller values. Each consumer's maximum potential demand is assumed to be one unit of the product. We assume that all consumers have a reservation value, $r$, for one unit of the product.

Given the above assumptions about firms and the market, the surplus $-\phi\left(\theta_{i}, x_{j i}\right)$ - that

\footnotetext{
${ }^{2}$ The equal size assumption is made to simplify the analysis. Assuming unequal sizes does not change any of the results presented in this section.

${ }^{3}$ While we assume two consumer types, the equilibrium results of the paper generalize to a continuum of consumer types whose valuations $\theta$ are uniformly distributed. Also given the spatial model we consider two firms and not multiple firms. But in alternative formulations using, for example, the representative consumer model (Perloff and Salop 1985) we could consider multiple firms and we would expect the effect of greater number of firms to be akin to lesser differentiation between the firms.

${ }^{4}$ Empirical evidence from retail markets provided by Hill and Juster (1985) supports this assertion that higherincome consumers have higher time costs and quality valuations. An earlier study by Maurizi and Kelley (1978) in retail gasoline markets finds an inverse relationship between income and search costs.
} 
consumer $i$ - of type $\theta_{i}$ who is located at a distance $x_{j i} \in[0,1]$ from retailer $j$ - gets from buying at retailer $j$ is given by, ${ }^{5}$

$$
\phi\left(\theta_{i}, x_{j i}\right)=\theta_{i} q_{j}-t \theta_{i} x_{j i}-p_{j} ; j=1,2
$$

where $q_{j}$ is non-negative. Each consumer is assumed to purchase the product that maximizes this surplus function. However, if the surplus from both products are less than zero, the consumer is assumed to purchase a competitive substitute.

We analyze the scenario where the entire market is served in equilibrium. Firms play a two-stage game. In the first stage, the quality levels, $q_{j}$, are simultaneously chosen by the two retailers. In the second stage, the prices, $p_{j}$, are chosen simultaneously by the two retailers, conditional on their chosen levels of quality (from the first stage). This assumption about two-stage decision making by firms is governed by the empirical reality that gasoline stations cannot easily change their service offerings in the short run. Typically, gasoline stations are built with a given set of station characteristics which are fixed, and pricing decisions are then taken conditional on the range of services represented in the station. Since this is a multistage game between firms, the equilibrium of the game should satisfy the sub-game perfection criterion. The demand facing retailer $j$ can be derived using the individual rationality and incentive compatibility constraints, as shown in equations (2) and (3) below.

$$
\begin{gathered}
\theta_{l} q_{j}-t \theta_{l} x_{j l}-p_{j} \geq 0 \\
\theta_{h} q_{j}-t \theta_{h} x_{j h}-p_{j} \geq 0 \\
\text { for } j=1,2
\end{gathered}
$$

In the full market coverage scenario, given that $x_{j i}$ is firm $j$ 's demand with consumer type $i$, then the corresponding demand of the competing firm is $\left(1-x_{j i}\right)$. Consequently, the incentive compatibility constraints are:

\footnotetext{
${ }^{5}$ This representation of consumer preferences is in the spirit of Mussa and Rosen (1978). Consider a quasilinear direct utility function $U\left(X, \alpha\left(Y\left(\theta_{i}\right)\right) q_{j}\right)+X_{0}$, where $X$ is one unit or none of the focal product, $X_{0}$ is a numeraire commodity which is measured in the same units as income, $Y\left(\theta_{i}\right)$ is consumer $i$ 's income (which is increasing in $\left.\theta_{i}\right), q_{j}$ is the quality level at retailer $j$, and $\alpha\left(Y\left(\theta_{i}\right)\right)$ is an income-based scale on the product $\left(\frac{\partial \alpha\left(Y\left(\theta_{i}\right)\right)}{\partial Y\left(\theta_{i}\right)}>0\right)$. Consumers choose their optimal bundle by maximizing utility subject to the budget constraint $p_{j} X+X_{0} \leq Y\left(\theta_{i}\right)-\tau\left(Y\left(\theta_{i}\right)\right) x_{j i}$, where $p_{j}$ is the price paid per-unit of the product, $\tau\left(Y\left(\theta_{i}\right)\right)$ is the travel cost such that $\frac{\partial \tau\left(Y\left(\bar{\theta}_{i}\right)\right)}{\partial Y\left(\theta_{i}\right)}>0$ and $x_{j i}$ is consumer $i$ 's distance from retailer $j$. Assuming small income effects, the consumer's optimization problem will yield an indirect utility form which can be specialized to (1).
} 


$$
\begin{gathered}
\theta_{l} q_{j}-t \theta_{l} x_{j l}-p_{j} \geq \theta_{l} q_{k}-t \theta_{l}\left(1-x_{j l}\right)-p_{k} \\
\theta_{h} q_{j}-t \theta_{h} x_{j h}-p_{j} \geq \theta_{h} q_{k}-t \theta_{h}\left(1-x_{j h}\right)-p_{k} \\
\text { for } j \neq k ; j, k=1,2
\end{gathered}
$$

From these conditions we can find the marginal consumers who determine the demand for each firm. For full market coverage the incentive compatibility constraints are the binding constraints. Using these constraints to solve firm 1's demand as $x_{1 i}=\frac{1}{2}+\frac{q_{1}-q_{2}}{2 t}-\frac{p_{1}-p_{2}}{2 t \theta_{i}}$ and for firm 2 it will be $x_{2 i}=\left(1-x_{2 i}\right)$. Let $\bar{x}_{j l}$ and $\bar{x}_{j h}$ represent the distance of the marginal consumer of the low valuation type and high valuation type from firm $j$. This means that the demand for firm $j$ is $\frac{\bar{x}_{j l}+\bar{x}_{j h}}{2}$. The profit function of firm $j$ is then,

$$
\pi_{j}=\left[\frac{\bar{x}_{j l}}{2}+\frac{\bar{x}_{j h}}{2}\right] p_{j}-\frac{q_{j}^{2}}{2}
$$

We first solve for the pricing stage of the game to find the optimal price of each firm as a function of the first stage qualities $p_{j}^{*}\left(q_{1}, q_{2}\right)$. Then we substitute these prices into the profit functions and solve for the optimal choice of the qualities.

\subsection{Analysis and Testable Predictions}

This section presents the implications of the model that can be subjected to empirical testing. We derive the symmetric and the asymmetric equilibria of this two-stage game. Solving for the first-order conditions with respect to prices chosen in the pricing sub-game, we get $p_{j}\left(q_{j}, s_{3-j}\right)=$ $\frac{2}{3} v \theta_{l} \frac{3 t+q_{j}-q_{3-j}}{v+1}$. Substituting these values into the objective function in (4), one gets the reducedform profit functions of the retailers $\pi_{j}\left(q_{j}, q_{3-j}\right)$ which can be used for the optimization with respect to quality. The first-order conditions of these profit functions can be evaluated for the best-response functions of each retailer for the other retailer's quality strategy.

$$
R_{j}\left(q_{3-j}\right)=q_{j}=2 v \theta_{l} \frac{3 t-q_{3-j}}{9 t(v+1)-2 v \theta_{l}}
$$

\subsection{The Symmetric Equilibrium}

Here we examine the conditions for a symmetric equilibrium, in which the two firms are undifferentiated in their chosen quality and price strategies (the details of the analysis are provided in the Appendix). To begin with note that the full market coverage scenario requires that $t$ be 
not too large or $t<\frac{4 v \theta_{l}}{3(5 v+1)}$. We find that in markets represented by $t_{s}=\frac{2 v \theta_{l}}{9(v+1)}<t<\frac{4 v \theta_{l}}{3(5 v+1)}$, the equilibrium is unique and symmetric. By solving the best response functions in (5) we get the quality and price choices in this symmetric equilibrium to be $q_{j}^{*}=\frac{2 v \theta_{l}}{3(v+1)}$ and $p_{j}^{*}=2 t \frac{v \theta_{l}}{(v+1)}$. Consider the condition $t>t_{s}$, and observe that the right-hand side of the inequality, $t_{s}$, increases with $v$. This means that the undifferentiated equilibrium is more likely in markets where the spread in quality valuations across consumers $(v)$ is sufficiently low, relative to the locational differentiation between the retailers $(t)$. Because a consumer's valuation of product quality can be seen as being determined by the consumer's income, a market with the undifferentiated equilibrium is interpreted to be one where the income variation across consumers is sufficiently low relative to the locational differentiation between the retailers. When retailers match price and quality, they compete symmetrically for either consumer type $\theta_{i}(i=l, h)$. While this protects their demand in each segment, the disadvantage is that the intensity of price competition is high when the locational differentiation between retailers is low. When the locational differentiation is high, however, the retailers are able withstand the effects of such price competition and the symmetric equilibrium ends up supporting a high enough price. Furthermore, with small differences in quality valuations across consumers, there are no substantial benefits to the firms from differentiating their price and quality strategies from each other, which sustains the symmetric equilibrium.

The symmetric equilibrium quality and price are both increasing in $v$. As expected, the equilibrium price increases in the locational differentiation between the retailers $(t)$, but the equilibrium quality is independent of $t .{ }^{6}$ The equilibrium profits of the retailers are given by $\pi_{j}^{*}=$ $\frac{v \theta_{l}\left[9 t(v+1)-2 v \theta_{l}\right]}{9(v+1)^{2}}$. As expected, the equilibrium profits go up with $t$. However, a greater spread in the quality valuations (i.e., larger $v$ ) decreases equilibrium profits if $t<\frac{4 v \theta_{l}}{9(v+1)}$. Given that $\frac{4 v \theta_{l}}{3(5 v+1)}<\frac{4 v \theta_{l}}{9(v+1)}$, this implies that the equilibrium profits are always decreasing in $v$ in the full market coverage case. To understand this, note that when the retailers choose their quality levels in the first stage, their decisions are governed more by the tastes of the high valuation consumers (because these consumers value quality the most). As the spread in the quality valuations increases, the retailers' quality choices become more inclined towards taking advantage of the high valuation segment and the equilibrium quality levels increase. Furthermore, the equilibrium

\footnotetext{
${ }^{6}$ Both price and quality are increasing in $\theta_{l}$ as well, because as $\theta_{l}$ increases, the average quality valuation in the market goes up.
} 
quality is independent of $t$, and so even as the locational differentiation between the retailers decreases, the chosen quality remains the same. However, as $t$ decreases, the prices that the retailers can charge goes down. In fact, if $t$ is small enough, the equilibrium profits decreases in $v$. In this sense, for sufficiently small values of $t$, relative to $v$, the intensity of competition under the symmetric equilibrium increases revealing a force towards differentiation in firm strategies.

\subsubsection{The Asymmetric Equilibrium}

When the extent of locational differentiation between the retailers $(t)$ becomes sufficiently low, relative to the spread in quality valuations across consumers $(v)$, we have the possibility of an asymmetric equilibrium. We derive an asymmetric equilibrium in which one firm (say, Firm 1) offers higher quality and price (and sells to the higher valuation segment), while the other firm offers lower quality and price (and sells to the lower valuation segment). In this case, the demand facing the two retailers can be derived using the following individual rationality and incentive compatibility constraints.

$$
\begin{aligned}
\theta_{h} q_{1}-t \theta_{h}-p_{1} & \geq 0 \\
\theta_{l} q_{2}-t \theta_{l}-p_{2} & \geq 0 \\
\theta_{h} q_{1}-t \theta_{h}-p_{1} & \geq \theta_{h} q_{2}-p_{2} \\
\theta_{l} q_{2}-t \theta_{l}-p_{2} & \geq \theta_{l} q_{1}-p_{1}
\end{aligned}
$$

We derive the equilibrium for the case in which equations (7) and (8) bind. ${ }^{7}$ From equation (6), we have $p_{2}=\theta_{l} q_{2}-t \theta_{l}$ and $p_{1}=p_{2}+\theta_{h}\left(q_{1}-q_{2}\right)-t \theta_{h}$. The profit functions of the two firms are $\pi_{1}=\frac{p_{1}}{2}-\frac{q_{1}^{2}}{2}$ and $\pi_{2}=\frac{p_{2}}{2}-\frac{q_{2}^{2}}{2}$. From this the quality levels can be derived to be $q_{1}^{*}=\frac{v \theta_{l}}{2}$ and $q_{2}^{*}=\frac{\theta_{l}}{2}$, and the price levels are $p_{1}^{*}=\frac{\theta_{l}^{2}}{2}[1+v(v-1)]-t \theta_{l}(v+1)$ and $p_{2}^{*}=\frac{\theta_{l}^{2}}{2}-t \theta_{l}$. From this it can be noted that the price charged by the high quality, high price retailer (i.e., Retailer 1) decreases in $t$ and increases in $v$, whereas the price charged by the low quality, low price retailer (i.e., Retailer 2) decreases in $t$ and is independent of $v$. In the Appendix, we derive the existence condition for the asymmetric equilibrium described above. It turns out that the equilibrium profits of Firm 1 and Firm 2 are positive if $t<\frac{\left(v^{2}-2 v+2\right)}{4(v+1)}$ and $t<\frac{1}{4}$, respectively. Given that

\footnotetext{
${ }^{7}$ One can alternatively solve the complementary case in which the binding constraints are (6) and (9). The insights from that case are analogous to those reported here.
} 
these profits are positive, the condition for the asymmetric equilibrium can be derived, as shown in the Appendix, to be $t<t_{a}=\min \left\{\frac{(v-1)^{2}}{2(v+1)}, \frac{v^{2}-2 v-2}{4(v-3)}\right\} .{ }^{8}$ In other words, the differentiated equilibrium is likely in markets where the locational differentiation between the retailers $(t)$ is sufficiently low, relative to the spread in quality valuations across consumers $(v)$.

\subsubsection{Qualitative Summary}

Traditional models of spatial competition predict that ex-ante symmetric retailers will choose symmetric strategies in equilibrium. Such a prediction does not necessarily follow in a market with both horizontal and vertical heterogeneity across consumers. We find that (1) location differentiation between retailers $(t)$, and $(2)$ spread in quality valuations across consumers $(v)$, jointly determine whether retailers will differentiate themselves on quality and price or not. Specifically, we show that if $v$ is sufficiently low relative to $t$, a symmetric equilibrium obtains, whereas if $t$ is sufficiently low relative to $v$, an asymmetric equilibrium obtains. Said differently, we find that ex-ante identical retailers located close to each other will engage in differentiated quality and price strategies when the spread in quality valuations among consumers in the local market is sufficiently large. This provides an explanation for why closely located gasoline stations sometimes choose different prices and sometimes do not.

\section{Empirical Analysis}

In this section, we present an empirical test of the qualitative implication of the theory presented in the previous section, that pertains to the inter-play of locational differentiation between retailers and spread in quality valuations in the market in determining equilibrium quality and pricing outcomes. For this purpose, we use survey data collected from the retail gasoline market in the Greater Saint Louis metropolitan area. Even though the basic product, i.e., gasoline, is a homogeneous product, retailers invest on different aspects of product design - which can be interpreted as the empirical manifestation of quality that is represented in the theoretical model $^{9}$ - using a variety of ancillary services, for example, pay-at-pump (i.e., the option to pay with a credit card at the pump), convenience store, car wash, service bay, full-service (i.e.,

\footnotetext{
${ }^{8}$ These conditions imply that for every $v$ as long as $t$ is small enough, there is an unique asymmetric outcome. And as long as $t$ is large enough, there will be a unique symmetric outcome.

${ }^{9}$ From this point onwards, product design and product quality will be used inter-changeably.
} 
pumping of gasoline by an attendant), the number of pumping bays etc. To the extent that competing gasoline stations can offer differing levels of such product design characteristics, they can also end up charging different prices on the same basic product, i.e., gasoline. In this sense, gasoline stations can differentiate from one another on both quality and price strategies, as in the theory. The empirical analysis tests the following two implications of the theoretical model (at the market-level).

1. For a given spread in quality valuations across consumers $(v)$, whether competing retailers adopt differentiated (undifferentiated) quality and pricing strategies depends on whether locational differentiation between retailers $(t)$ is low (high).

2. For a given level of locational differentiation between retailers $(t)$, whether competing retailers adopt differentiated (undifferentiated) quality and pricing strategies depends on whether the spread in quality valuations across consumers $(v)$ is high (low).

In order to undertake the empirical analysis, we need to first identify a suitable number of local markets, and then create empirical proxies, at the market-level, for (1) the extent of differentiation in quality strategies across retailers $\left(\Delta q_{j}\right),(2)$ the extent of differentiation in pricing strategies across retailers $\left(\Delta p_{j}\right),(3)$ spread in quality valuations across consumers $(v)$, (4) locational differentiation between retailers $(t)$. Testing the two implications given above would then involve a statistical test of whether $\Delta q_{j}$ and $\Delta p_{j}$ both jointly increase as (1) $v$ increases (holding $t$ constant), and (2) $t$ decreases (holding $v$ constant).

Suppose we identify local markets for retail gasoline in geographic space (as will be made clear later). In the theory we had indicated that $\theta_{i}$ is related to consumer income, and therefore an empirical proxy for the spread in quality valuations, $v$, is the income spread across consumers in the local market. Both the standard deviation, and the coefficient of variation, of $\theta_{i}$ are increasing in $v$, which makes them good empirical proxies for $v$. A good empirical proxy for $t$ would be the number of gasoline stations competing within the market on a per unit geographical area basis, so that locational differentiation between retailers is likely to be lower as the number of retailers per unit area is higher. Said differently, the local competitive intensity, which is inversely related to $t$, increases with the number of retailers per unit area in the market. An empirical proxy of $\Delta q_{j}$ would be the variance of a composite measure of quality (suitably defined using the 
station characteristics represented at stations, as will be explained later) across all retailers in the market, while an empirical proxy of $\Delta p_{j}$ would be the variance of price across all retailers in the market.

\subsection{Data Description}

We employ survey data, ${ }^{10}$ collected during 1999, which covers 731 retail gasoline stations in five counties - Franklin, Jefferson, St. Charles, St. Louis, St. Louis City - in St. Louis, Missouri. The survey data contain information on retail prices and various service and local market characteristics pertaining to the 731 gasoline stations. We also employ the 2000 U.S census records to construct information on demographic characteristics of the local markets where these gasoline stations operate (www.census.gov). Lastly, we collect information on the geometric land areas of census tracts from the Missouri Census Data Center (www.mcdc2.missouri.edu).

The survey data include, for each gasoline station, the prices of three grades - 87, 89 and 93 octane levels - of gasoline along with station-specific service characteristics, i.e., brand name, number of gasoline pumps, operating hours, presence of full-service, convenience store, pay-atpump facility, car wash, service bay, oil/lube service, and acceptability of credit cards. The survey data also include information on the visibility of gasoline stations from one another, specifically, the number of other gasoline stations that are visible from each station and also other market characteristics such as the traffic flows on streets adjacent to the station and proximity to freeways. The address of each station is also recorded in the survey data. Using the census data, which contain demographic information - income, population, age distribution, home value, education levels etc. - at the level of census tract, ${ }^{11}$ and by matching gasoline stations' addresses with their corresponding census tract on an area map, we construct a demographic profile for each gasoline station's local market. Six of the gasoline stations in our survey data are in census tract groups for which demographic information is unavailable. Therefore, we exclude these gasoline stations, which leaves us with 724 usable gasoline stations for our empirical analysis. Using the information in the Missouri Census Data Center web site, we also construct the geometric land areas of the census tracts in which the gasoline stations are located.

\footnotetext{
${ }^{10}$ The survey data was collected by a marketing research firm, New Image Marketing Limited, based in Fort Myers, Florida.

${ }^{11}$ Each census tract has multiple - typically one or two, and sometimes three - block groups, and the census tracks demographics at the level of block group within each census tract.
} 


\subsection{Empirical Measures}

The demographic profile of each gasoline station's local market is characterized using two measures, both of which are computed using the income distribution of the appropriate census tract: $A V G$ measures the average income of the local market, SPREAD measures the standard deviation of the income of the local market. The price measure used in the analysis, PRICE, is the observed (posted) price of self-service gasoline in dollars per gallon. Since 87-octane level is the most commonly sold grade of gasoline in gasoline markets, and is available at all the gasoline stations in our dataset, we operationalize the price measure using the price of this grade of gasoline. Table 1 reports the descriptive statistics on the demographic profiles and gasoline prices at the 724 gasoline stations in our dataset.

\begin{tabular}{rrrrr}
\hline \hline Variable & Mean & Std.Dev. & Min. & Max. \\
\hline AVG & $\$ 54,142$ & $\$ 21,793$ & $\$ 11,944$ & $\$ 177,668$ \\
SPREAD & $\$ 37,914$ & $\$ 14,135$ & $\$ 6,211$ & $\$ 87,366$ \\
PRICE & $\$ 0.96$ & $\$ 0.05$ & $\$ 0.86$ & $\$ 1.16$ \\
\hline
\end{tabular}

Table 1: Descriptive Statistics on Station-Level Demographics and Prices Based on 724 Gasoline Stations.

It is clear from Table 1 that there is significant cross-station heterogeneity in terms of not only the average income of the local market being served $(A V G)$, but also the standard deviation of income in the local market (SPREAD). For example, the standard deviations for $A V G$ and SPREAD are $\$ 21,793$ and $\$ 14,135$, respectively, which are $40 \%$ and $37 \%$ of their respective averages of $\$ 54,142$ and $\$ 37,914$. Gasoline prices, however, are observed to show only a modest amount of variation across the 724 stations, with a coefficient of variation of 0.05 .

Measures of relevant station characteristics are as follows: NOZ is a discrete variable, whose values range from 2 to 8 , that captures the number of pumping nozzles at the gasoline station; $P A Y$ is an indicator variable that takes the value 1 if the station has pay-at-pump facility and 0 otherwise; $W A S H$ is an indicator variable that takes the value 1 if the station has car wash facility and 0 otherwise; $C O N V$ is an indicator variable that takes the value 1 if the station has a convenience store and 0 otherwise; $B A Y$ is an indicator variable that takes the value 1 if the station has a service bay and 0 otherwise; FULL is an indicator variable that takes the value 1 if the station has full-service pumps and 0 otherwise; $B R A N D$ is an indicator variable that 
takes the value 1 if the station is a brand-name station (Amoco, Shell or Exxon-Mobil) and 0 otherwise; and HOURS is an indicator variable that takes the value 1 if the station is open 24 hours day and 0 otherwise. Tables 2 and 3 report the observed frequencies of the values of these indicator variables across the stations in our dataset.

\begin{tabular}{rrrrrrrrrr}
\hline \hline Variable & 1 & 2 & 3 & 4 & 5 & 6 & 7 & 8 & $>8$ \\
\hline NOZ & 3 & 69 & 125 & 314 & 44 & 126 & 8 & 32 & 3 \\
\hline
\end{tabular}

Table 2: Descriptive Statistics on Station Characteristics Based on 724 Gasoline Stations.

\begin{tabular}{rrrrrrrr}
\hline \hline Value & PAY & WASH & CONV & BAY & FULL & BRAND & HOURS \\
\hline 0 & 256 & 561 & 182 & 582 & 633 & 420 & 226 \\
1 & 468 & 163 & 542 & 142 & 91 & 304 & 498 \\
\hline
\end{tabular}

Table 3: Descriptive Statistics on Station Characteristics Based on 724 Gasoline Stations.

From Table 2, it is observed that a majority of gasoline stations (71\%) have 4 pumps or less, with $43 \%$ of all stations having exactly 4 pumps. From Table 3, it is observed that $65 \%$ of all stations have pay-at-pump, $29 \%$ have car-wash, $75 \%$ have a convenience store, $20 \%$ have a service bay, $13 \%$ have full-service, and $42 \%$ are brand-name stations.

Since the model deals with competition between gasoline stations within markets, we have to operationalize our empirical measures, and create a dataset, at the level of local markets, and not at the level of individual gasoline stations. For this purpose, we define local markets for retail gasoline to be census tracts. ${ }^{12}$ There are 263 census tracts which collectively account for the 724 stations in our data. However, 77 of these census tracts contain only one retail gasoline station. Since these census tracts effectively represent local monopoly markets for retail gasoline, they are excluded from the analysis (since our analysis pertains to competitive markets). This results in our retaining a total of 647 gasoline stations from our original set of 724 stations (after excluding the 77 local monopoly stations), that together represent 186 local markets. These local markets are, by definition (since they are different census tracts), mutually exclusive, i.e.,

\footnotetext{
${ }^{12}$ We can alternatively operationalize local markets by observationally classifying stations into different mutually exclusive markets by using a subjective, but consistent, heuristic. For example, in previous research, markets have been defined based on stations that fall within a circle of half a mile or one mile radius. We use census tracts on account of their objective definitions in the U.S. census. However, in an earlier version of this paper we had constructed markets using a subjective heuristic that involved markets with a half mile radius and the qualitative results are similar to what are reported here.
} 
different local markets do not share stations in common (as in Bresnahan and Reiss 1991), and are collectively exhaustive of the St. Louis market. Among these 186 mutually exclusive local markets, 72 have two gasoline stations, 44 have three stations, 35 have four stations, 15 have five stations, 8 have six stations, 4 have seven stations, 4 have eight stations, and 4 have nine stations or more. ${ }^{13}$

The demographic characteristics, specifically SPREAD, of each of these 186 local markets are obtained directly from the 2000 US census. We construct a measure $N U M$, which captures the number of gasoline stations within the local market. We then scale the variable $N U M$ by $A R E A$, the geographic land area of the local market. The variable $N U M / A R E A$ represents the density of stations in the local market. This would be a measure of locational differentiation (or local competitive intensity) among stations within the market area, with a higher value of $N U M / A R E A$ representing lower locational differentiation (and, therefore, higher local competitive intensity) between stations in the local market. As an alternative to $N U M / A R E A$, we also construct a second measure of locational differentiation, $V I S \in[0,1]$, which captures the relative visibility of stations within the local market. This is computed as follows: For each station $i$ in a local market $m$, we count the total number of stations that are visible from it, say, $n_{i}$. We also calculate the theoretical maximum number of stations that can be visible from it, say $N_{i}$, and this will be equal to the total number of stations in the market, $n_{m}$, minus one. VIS is then computed as $\frac{\sum_{i=1}^{n_{m}} n_{i}}{\sum_{i=1}^{n_{m}} N_{i}}$ which becomes $\frac{\sum_{i=1}^{n_{m}} n_{i}}{n_{m}\left(n_{m}-1\right)} \cdot{ }^{14}$ In Table 4, we report the descriptive statistics of these demographic variables across the 186 local markets in our study. It is clear that $S P R E A D$ shows a lot of variation across local markets, which suggests that markets range from being quite homogeneous in terms of their income distributions to being very heterogeneous. $N U M / A R E A$

\footnotetext{
${ }^{13}$ One question pertaining to the use of the census tract as a measure of local markets is whether stations within a census tract compete more with each other than with stations in adjoining census tracts. Since this is more likely to be a problem for stations at the periphery of census tracts, we conducted the following analysis: For each census tract $i$, we calculated the centroid of the locations of stations within the tract. Denote this centroid by $C(i)$. We then calculated the average distance of stations within census tract $i$ from $C(i)$. Denote this average distance by be $d(i)$. We then identified the peripheral station of census tract $i$ as the station which was farthest from centroid $C(i)$. Denote this peripheral station by $P(i)$. Last, we calculated the distance of $P(i)$ from the centroid of the nearest census tract outside census tract $i$. Denote this distance by $D(i)$. We found that for 156 out of 186 census tracts in our dataset, $d(i)<D(i)$. We could reject the null hypothesis that a peripheral station is just as likely to be correctly classified as it is to be wrongly classified, in terms of whether the station's rightful market is its own census tract or not, at the 0.01 level of significance.

${ }^{14}$ For example, suppose a local market has 3 stations. The theoretical maximum visibility is $3 * 2=6$.
} 
also shows a lot of variation across local markets which suggests significant differences across local markets in terms of local competitive intensities among gasoline stations.

Next, we need the price and product quality differentiation measures at the level of local markets. We construct these measures by computing the within-market standard deviations of PRICE as well as the eight station characteristics measures, i.e., NOZ, PAY, WASH, $C O N V, B A Y, F U L L, B R A N D$, and $H O U R S$ across all stations within each local market. These yield, for each of the 186 local markets in our dataset, a price differentiation measure PRICEDIF, and eight different quality differentiation measures: NOZDIF, PAYDIF, WASHDIF, CONVDIF, BAYDIF, FULLDIF, BRANDDIF and HOURSDIF. In Table 5, we report the descriptive statistics of these measures across the 186 local markets in our study. We can see that the observed range of these measures across local markets is identical - 0 to 0.7071 - for eight of the nine quality differentiation measures, which is because of the binary aspect of those eight service outcomes. For the remaining service outcome that takes multiple ordinal values $(N O Z)$, the corresponding differentiation measure $(N O Z D I F)$ is observed to range up to a larger value (1.1547) across local markets.

\begin{tabular}{rrrrr}
\hline \hline Variable & Mean & Std.Dev. & Min. & Max. \\
\hline SPREAD & $\$ 38,607$ & $\$ 13,580$ & $\$ 17,003$ & $\$ 85,390$ \\
NUM/AREA & $2.26 /$ sq.mi. & $2.26 /$ sq.mi. & $0.01 /$ sq.mi. & $13.7 /$ sq.mi. \\
VIS & 0.2331 & 0.3651 & 0 & 2 \\
\hline
\end{tabular}

Table 4: Descriptive Statistics on Key Exogenous Variables Based on 186 Local Markets.

\begin{tabular}{rrrrr}
\hline \hline Variable & Mean & Std.Dev. & Min. & Max. \\
\hline PRICEDIF & $\$ 0.023$ & $\$ 0.023$ & $\$ 0$ & $\$ 0.122$ \\
NOZDIF & 1.1417 & 0.7891 & 0 & 1.1547 \\
PAYDIF & 0.3464 & 0.2886 & 0 & 0.7071 \\
WASHDIF & 0.2908 & 0.2911 & 0 & 0.7071 \\
CONVDIF & 0.2596 & 0.2888 & 0 & 0.7071 \\
BAYDIF & 0.2543 & 0.2861 & 0 & 0.7071 \\
FULLDIF & 0.1618 & 0.2538 & 0 & 0.7071 \\
BRANDIF & 0.4222 & 0.2686 & 0 & 0.7071 \\
HOURSDIF & 0.3179 & 0.2903 & 0 & 0.7071 \\
\hline
\end{tabular}

Table 5: Descriptive Statistics on Endogenous Variables Based on 186 Local Markets. 


\subsection{Econometric Model}

The theoretical model involves two endogenous variables at the local market-level - price differentiation and quality differentiation. The first variable is operationalized using the PRICEDIF measure. The second variable can be operationalized using any or all of the eight different measures, NOZDIF, PAY DIF, WASHDIF, CONVDIF, BAYDIF, FULLDIF, BRANDDIF and HOURSDIF.

Recall that in the theory, these endogenous variables are functions of two factors: one, locational differentiation between the competing retailers $(t)$; two, the heterogeneity in quality valuations across consumers $(v)$. In the econometric model, these two factors are operationalized as follows: The locational differentiation between retailers $(t)$ is represented by the explanatory variable $N U M / A R E A$, which measures the extent of locational proximity between stations competing in a local market. ${ }^{15}$ To operationalize heterogeneity in quality valuations $(v)$, we use the standard deviation of income of the local market (SPREAD) since the standard deviation is increasing in $v$. According to the predictions of the theory, if we ran an appropriate regression of the price differentiation variable and the product quality differentiation variable(s) versus the two explanatory variables (i.e., $N U M / A R E A$ and $S P R E A D$ ), the coefficients of both variables must be positive and significant in each regression.

We re-code the price differentiation variable as well as the product quality differentiation variables as taking one of two discrete values - Low $(=0)$ or High $(=1)$ - depending on a cut-off point that is determined as the median of the underlying continuous variables' observed values in our dataset. The coding procedure is reported in Table 6 .

Having coded each endogenous variable as a binary, discrete outcome, we can use a multivariate logit model (Grizzle 1971, Niraj, Padmanabhan and Seetharaman 2008) - specifically, an nonavariate logit model - to explain the price and quality differentiation outcomes jointly as functions of the two covariates, $N U M / A R E A$ and $S P R E A D .{ }^{16}$ The multivariate logit model is specified at the level of a local market as shown below.

\footnotetext{
${ }^{15}$ An alternative measure of locational differentiation is $V I S$, which represents the effects of relative visibility of these stations from each other.

${ }^{16}$ Note that the multivariate logit model is used to explain multiple correlated binary outcomes, as opposed to the multinomial logit model that is used to explain single multinomial outcomes. Another model that applies to correlated binary outcomes is the multivariate probit model (Ashford and Sowden 1970). However, unlike the multivariate logit, it does not have a likelihood function with an analytical closed-form, which renders it computationally unattractive.
} 


\begin{tabular}{rrrrr}
\hline \hline Variable & Low $=0$ & High $=1$ & $\# 0 s$ & $\# 1 s$ \\
\hline PRICEDIF & $\$ \leq 0.015$ & $\$>0.015$ & 33 & 153 \\
NOZDIF & $\leq 1.1547$ & $>1.1547$ & 32 & 154 \\
PAYDIF & $\leq 0.5$ & $>0.5$ & 74 & 112 \\
WASHDIF & $\leq 0.3790$ & $>0.3790$ & 90 & 96 \\
CONVDIF & $=0$ & $>0$ & 100 & 86 \\
BAYDIF & $=0$ & $>0$ & 101 & 85 \\
FULLDIF & $=0$ & $>0$ & 130 & 56 \\
BRANDIF & $\leq 0.5284$ & $>0.5284$ & 93 & 93 \\
HOURSDIF & $\leq 0.4551$ & $>0.4551$ & 82 & 104 \\
\hline
\end{tabular}

Table 6: Binary Coding of Endogenous Variables.

$$
\pi_{t}\left(I_{1 t}, I_{2 t}, \ldots, I_{9 t}\right)=\frac{e^{\sum_{c=1}^{9}\left(\alpha_{c}+X_{c t} \beta_{c}\right) I_{c t}+\sum_{c<c^{\prime}} \gamma_{c c^{\prime}} I_{c t} I_{c^{\prime} t}}}{\sum_{I_{1 t}=0}^{1} \cdot \sum_{I_{9 t}=0}^{1} e^{\sum_{k=1}^{9}\left(\alpha_{k}+X_{k t} \beta_{k}\right) I_{k t}+\sum_{k<k^{\prime}} \gamma_{k k^{\prime}} I_{k t} I_{k^{\prime} t}}},
$$

where $\pi_{t}\left(I_{1 t}, I_{2 t}, \ldots, I_{9 t}\right)$ is the joint probability associated with the nine endogenous discrete variables $I_{c}(c=1$. PRICE, 2. NOZDIF, 3. PAYDIF, 4. WASHDIF, 5. CONVDIF, 6. BAYDIF, 7. FULLDIF, 8. BRANDDIF, 9. HOURSDIF) in market $t$, where $I_{c t}$ is an indicator variable that takes the value 1 if variable $c$ takes the value High in market $t$ and 0 otherwise, $\alpha_{c}$ is an intercept parameter associated with variable $c$ (capturing the baseline propensity of a local market to have high differentiation on dimension $c$ ), $X_{c t}$ is a two-dimensional vector of covariates (i.e., $N U M / A R E A$ and $S P R E A D)$ corresponding to market $t, \beta_{c}$ is the corresponding two-dimensional vector of slope parameters capturing the effects of $N U M / A R E A$ and $S P R E A D$ on variable $c$, and $\gamma_{c c^{\prime}}$ captures the covariance between endogenous variables $I_{c t}$ and $I_{c^{\prime} t}$. The appropriateness of the multivariate logit model over, say, nine independent binary logit models to explain the observed price and quality differentiation outcomes arises on account of these parameters $\gamma_{c c^{\prime}}$. They capture the correlations in the unobservables between the price differentiation and quality differentiation measures at the market-level, and therefore yield a system of simultaneous estimable equations as opposed to a system of independent estimable equations. Our model would imply that the $\beta_{c}$ 's are positive.

In order to control for extraneous (i.e., outside the scope of our theory) drivers of observed price and quality differentiation outcomes within local markets, we construct and include the 
following additional market-level variables ("controls") as covariates within the vector $X_{c t}$ in the multivariate logit model.

1. TRAFFICDIF: This is the standard deviation of the local traffic (TRAFFIC) conditions across all gasoline stations within the local market. TRAFFIC is an ordinal variable that takes the following 7 values: 1 if jam-packed (less than 15 miles per hour), 2 if very congested (15-20 miles per hour), 3 if congested but moving (less than speed limit), 4 if heavy but moving (near speed limit), 5 if moderate but moving (at speed limit), 6 if light (better than speed limit), and 7 if sporadic. This variable is found to mostly take values of 3 , 4 or 5 for gasoline stations in our dataset, with $27 \%, 36 \%$ and $24 \%$ of stations showing values 3,4 and 5 , respectively.

2. FREEWAYMEAN: This is the average value of a station's proximity to the freeway (FREEWAY) across all gasoline stations within the local market. It is possible that stations closer to a freeway may face more heterogeneous consumer populations. FREEWAY is an indicator variable that takes the value 1 if the station is within 1 mile from a freeway, and 0 otherwise. In our dataset, we find that 150 out of the 724 stations have $F R E E W A Y=1$.

3. GINIOPER and GINIBLDG: The first variable GINIOPER is a Gini index computed across the operation types $(O P E R)$ of all gasoline stations within the local market. OPER is a nominal variable that takes the value 1 for lessee-dealer, 2 for salary operation, 3 for open dealer, and 4 for jobber/wholesaler. In our dataset, we find 145, 103, 148 and 328 stations, respectively, to take values 1, 2, 3 and 4 for OPER. Similarly, GINIBLDG is a Gini index computed across the building ownership types $(B L D G)$ of all gasoline stations within the local market. $B L D G$ is a nominal variable that takes the value 1 if a major oil company owns the building, 2 if a non-major or regional oil company owns the building, 3 if a local distributor or oil company owns the building, 4 if the individual who runs the operation owns the building, and 5 if a real-estate or a non-oil related company owns the building. In our dataset, we find 187, 62, 228, 148 and 99 stations, respectively, to take 
values $1,2,3,4$ and 5 for $B L D G .^{17}$

We include TRAFFICDIF, GINIOPER, and GINIBLDG as control variables in the multivariate logit model using the rationale that the observed differentiation in pricing and service outcomes in a local market could be, in part, because of observed differences in these variables. TRAFFICDIF reflects the possibility that persistent differences in traffic conditions would affect station demand and thereby lead to differences in behavior across the stations. The two Gini index variables represent the fact that observed differences in station ownership types and building ownership types could result in differences in station behavior. We also include FREEWAYMEAN as a control variable to accommodate the possibility that observed price and service differentiation outcomes could be systematically different in local markets that are close to the freeway when compared to other markets. In Table 7, we report the descriptive statistics of these measures across the 186 local markets in our study. We see that all of the control variables show a good amount of variation across local markets.

\begin{tabular}{rrrrr}
\hline \hline Variable & Mean & Std.Dev. & Min. & Max. \\
\hline TRAFFICDIF & 0.6352 & 0.5206 & 0 & 2.1213 \\
FREEWAYMEAN & 0.1968 & 0.1581 & 0 & 1 \\
GINIOPER & 0.4201 & 0.2186 & 0 & 0.75 \\
GINIBLDG & 0.4774 & 0.2070 & 0 & 0.8 \\
\hline
\end{tabular}

Table 7: Descriptive Statistics on Exogenous Control Variables Based on 186 Local Markets.

While the multivariate logit model captures the interdependencies between the nine marketlevel outcomes, it does entail the estimation of a large number of parameters, specifically, 36 $\gamma_{c c^{\prime}}$ 's. Because we have only 186 observations for estimation purposes, this presents an estimation problem. One way around this problem is to reduce the dimensionality of the estimable parameter space by reducing eight quality dimensions to a smaller number of quality dimensions. For example, we can treat PRICEDIF and, in sequence, one of the eight service quality differentiation measures, as two simultaneous outcomes in a bivariate (instead of a nonavari-

${ }^{17}$ The index GINIOPER for a local market is calculated as $\sum_{q=1}^{4} \operatorname{Pr}(O P E R=q)^{2}$, where $\operatorname{Pr}(O P E R=q)$ represents the fraction of stations within the market with $O P E R=q$. Similarly, GINIBLDG is calculated as $\sum_{q=1}^{5} \operatorname{Pr}(B L D G=q)^{2}$, where $\operatorname{Pr}(B L D G=q)$ represents the fraction of stations within the market with $B L D G=q$ 
ate) logit model. As an alternative approach, one could recognize that among the eight service dimensions under analysis, some of the dimensions can directly be seen as a vertical quality characteristic in the sense that consumers would always like more of this characteristic than less at equal prices. We classify the five dimensions BRAND, HOURS, NOZ, PAY and FULL - pertain more directly to quality. ${ }^{18}$ The remaining three dimensions - CONV,WASH and $B A Y$ can be seen as dimensions which may not only add to consumer perception of station quality but which in addition also qualify as complementary products for gasoline. Under such a recognition, one could estimate a trivariate logit model, with PRICEDIF, *DIF (where $*=B R A N D, H O U R S, N O Z, P A Y$ or FULL), and $* * D I F$ (where $* *=C O N V, W A S H$ or $B A Y)$ as simultaneous outcomes in the model. We take this latter approach, allowing each of the three outcomes of the multivariate logit model to be a function of $N U M / A R E A$ and $S P R E A D$. This approach involves the estimation of only $3 \gamma_{c c^{\prime}}$ 's at a time. It also means that we estimate a total of fifteen different trivariate logit models on our market-level data.

\subsection{Estimation and Testing the Predictions}

In order to estimate the parameters of the trivariate logit model, we maximize the following sample likelihood function.

$$
L=\prod_{m=1}^{186} \prod_{i_{1}=0}^{1} \prod_{i_{2}=0}^{1} \prod_{i_{3}=0}^{1} \pi_{m t}\left(I_{1 t}=i_{1}, I_{2 t}=i_{2}, I_{3 t}=i_{3}\right)^{\delta_{m i 1 i 2 i 3}},
$$

where $\delta_{m i 1 i 2 i 3}$ is an indicator variable that takes the value 1 if local market $m$ is characterized by $\left(I_{1 t}=i_{1}, I_{2 t}=i_{2}, I_{3 t}=i_{3}\right)$ and the value 0 otherwise (note: $I_{1 t}$ stands for PRICEDIF, $I_{2 t}$ stands for $* D I F$, and $I_{3 t}$ stands for $* * D I F$. The likelihood function is maximized using gradient-based techniques to obtain estimates of model parameters. Our model's predictions are that the slope coefficients (i.e., three pairs of coefficients on $N U M / A R E A$ and $S P R E A D$ ) in the trivariate logit model must be positive and significant.

\subsection{Empirical Results}

Our main empirical analysis involves a trivariate logit model, where PRICEDIF, $* D I F$ and * $* D I F$ are simultaneously modeled as functions of $N U M / A R E A$ and SPREAD. However,

\footnotetext{
${ }^{18}$ Png and Reitman (1994) document the importance of the number of pumps as a quality differentiation variable.
} 
we begin with a first-level analysis using a univariate logit model where each outcome among PRICEDIF, BRANDDIF, HOURSDIF, NOZDIF, PAYDIF, FULLDIF, CONVDIF, $W A S H D I F$, and $B A Y D I F$ are sequentially modeled as functions of $N U M / A R E A$ and $S P R E A D$.

\subsubsection{Univariate Logit Results}

The results from estimating nine different univariate logit models are reported in Tables 8 and 9 . The coefficients of the key variables are reported in Table 8. In seven out of the nine cases, the effect of $S P R E A D$ is found to be positive and significant (with the strongest effects, in terms of the estimated magnitude of the coefficient, occurring for HOURSDIF and FULLDIF), which is consistent with the implications of the theory. For NOZDIF and PAYDIF, the effect of $S P R E A D$ is found to be insignificant. Further, in seven out of the nine cases, the effect of $N U M / A R E A$ is found to be positive and significant (with the strongest effects, in terms of the estimated magnitudes of the coefficients, occurring for CONVDIF and FULLDIF), which is also consistent with the implications of our theory. For HOURSDIF and WASHDIF, the effect of $N U M / A R E A$ is found to be insignificant. Overall, these results strongly support the implications of our theory.

The coefficients of the control variables are reported in Table 9. We also find that three of the control variables - TRAFFICDIF, GINIOPER and GINIBLDG - are found to have the hypothesized positive effects on the outcome variables.

\begin{tabular}{rrrr}
\hline \hline Outcome & Intercept & SPREAD/1000 & NUM/AREA \\
\hline PRICEDIF & $-3.0320(0.8436)$ & $0.0279(0.0126)$ & $0.0802(0.0334)$ \\
BRANDDIF & $-0.9474(0.7422)$ & $0.0257(0.0120)$ & $0.0234(0.0092)$ \\
HOURSDIF & $-2.5774(0.8208)$ & $0.0447(0.0136)$ & $-0.0112(0.0734)$ \\
NOZDIF & $-0.4409(0.7537)$ & $-0.0116(0.0116)$ & $0.0057(0.0027)$ \\
PAYDIF & $-0.5789(0.7519)$ & $-0.0071(0.0121)$ & $0.0914(0.0426)$ \\
FULLDIF & $-3.6756(0.9480)$ & $0.0356(0.0129)$ & $0.1726(0.0759)$ \\
CONVDIF & $-2.7710(0.8332)$ & $0.0227(0.0122)$ & $0.2991(0.0908)$ \\
WASHDIF & $-0.2804(0.7449)$ & $0.0114(0.0019)$ & $-0.1182(0.0738)$ \\
BAYDIF & $-3.2192(0.8884)$ & $0.0182(0.0023)$ & $0.1464(0.0784)$ \\
\hline
\end{tabular}

Table 8: Univariate Logit Results - Coefficients of Key Variables ( Standard errors within parentheses). 


\begin{tabular}{rrrrr}
\hline \hline Outcome & TRAFFICDIF & FREEWAYMEAN & GINIOPER & GINIBLDG \\
\hline PRICEDIF & $0.6906(0.3131)$ & $0.3372(0.5284)$ & $1.6889(0.8463)$ & $0.6254(0.3268)$ \\
BRANDDIF & $0.2450(0.1236)$ & $-0.0623(0.5626)$ & $-1.4985(1.0834)$ & $0.9007(0.5366)$ \\
HOURSDIF & $0.3172(0.1208)$ & $-0.2778(0.5238)$ & $0.8204(0.4114)$ & $1.1824(0.5867)$ \\
NOZDIF & $0.2677(0.1937)$ & $0.0555(0.5222)$ & $0.7938(0.3586)$ & $0.7745(0.3722)$ \\
PAYDIF & $0.6371(0.3025)$ & $-0.5198(0.5142)$ & $0.0959(1.0769)$ & $0.3936(0.3927)$ \\
FULLDIF & $0.1069(0.0803)$ & $-0.3490(0.5692)$ & $1.0247(0.6355)$ & $1.5431(0.7494)$ \\
CONVDIF & $-0.1243(0.3094)$ & $0.4350(0.5472)$ & $2.2532(1.2191)$ & $-0.3259(1.2716)$ \\
WASHDIF & $0.3000(0.1947)$ & $-0.7157(0.5145)$ & $-0.1228(1.3340)$ & $1.1389(0.5735)$ \\
BAYDIF & $0.1721(0.0854)$ & $0.2025(0.5431)$ & $1.8459(0.9812)$ & $1.8980(0.9089)$ \\
\hline
\end{tabular}

Table 9: Univariate Logit Results - Coefficients of Control Variables ( Standard errors within parentheses ).

\subsubsection{Trivariate Logit Results}

The results from estimating fifteen different specifications of the trivariate logit model are reported in Tables $10-14 .{ }^{19}$ As far as unobserved correlations among outcomes are concerned, the following pair-wise correlations are found to be positive and significant: (1) PRICEDIF and CONVDIF (Tables 10, 11, 12, 13, 14), (2) PRICEDIF and BAYDIF (Tables 10, 11, 12, 13), (3) HOURSDIF and WASHDIF (Table 11), (4) HOURSDIF and CONVDIF (Table 11), (5) HOURSDIF and BAYDIF (Table 11), (6) FULLDIF and CONVDIF (Table 14), (7) PRICEDIF and FULLDIF (Table 14). The following pair-wise correlations are found to be negative and significant: (1) BRANDDIF and CONVDIF (Table 10), and (2) PAYDIF and WASHDIF (Table 13). This implies that at least some of the outcome variables are jointly endogenous for reasons unobserved by the econometrician, and vindicates our employment of the multivariate logit model (over independent univariate logit models).

In thirty eight out of the forty five cases represented in Tables 10-14, the effect of $S P R E A D$ is found to be positive and significant, which is strongly consistent with the implications of our theory. For $N O Z D I F$ and $P A Y D I F$, the effect of $S P R E A D$ is found to be insignificant in all cases. These findings are all consistent with those obtained using the univariate logit models earlier (see Tables 8-9).

In thirty six out of the forty five cases represented in Tables 10-14, the effect of $N U M / A R E A$ is found to be positive and significant, which is strongly consistent with the implications of our theory. For HOURSDIF and WASHDIF, the effect of $N U M / A R E A$ is found to be

\footnotetext{
${ }^{19}$ Only the coefficients of the key variables are reported in Tables 10-14. The effects of control variables are consistent with those reported for the univariate logits in Tables 8-9 and are reported in the Appendix.
} 
insignificant in all cases. These findings are all qualitatively similar to those obtained using the univariate logit models earlier (see Tables 8-9).

Overall, the results from the trivariate logit models strongly support the implications of our theoretical model. Also, three of the control variables - TRAFFICDIF, GINIOPER and GINIBLDG - are found to have the hypothesized positive effects on the outcome variables, and these results are also consistent with those obtained using the univariate logit models (see Tables 8-9). ${ }^{20}$

\begin{tabular}{rrrr}
\hline \hline Outcome & Intercept & SPREAD/1000 & NUM/AREA \\
\hline MODEL1 & & & \\
PRICEDIF & $-3.0801(0.9064)$ & $0.0234(0.0114)$ & $0.0152(0.0091)$ \\
BRANDDIF & $-1.0635(0.6474)$ & $0.0307(0.0026)$ & $0.0746(0.0036)$ \\
CONVDIF & $-2.5838(0.8572)$ & $0.0232(0.0111)$ & $0.3103(0.0948)$ \\
$\gamma_{12}$ & $0.0561(0.3067)$ & & \\
$\gamma_{13}$ & $1.0970(0.3481)$ & & \\
$\gamma_{23}$ & $-0.8531(0.3402)$ & & \\
$M O D E L 2$ & & & \\
PRICEDIF & $-3.0111(0.8736)$ & $0.0287(0.0128)$ & $0.0820(0.0338)$ \\
BRANDDIF & $-0.9594(0.8592)$ & $0.0267(0.0119)$ & $0.0253(0.0073)$ \\
$W A S H D I F$ & $-0.2672(0.8167)$ & $0.0113(0.0017)$ & $-0.1187(0.0746)$ \\
$\gamma_{12}$ & $-0.1427(0.3195)$ & & \\
$\gamma_{13}$ & $0.0341(0.1729)$ & & \\
$\gamma_{23}$ & $-0.0275(0.2521)$ & & \\
$M O D E L 3$ & & & \\
$P R I C E D I F$ & $-2.9545(0.8562)$ & $0.0258(0.0129)$ & $0.0504(0.0237)$ \\
$B R A N D D I F$ & $-0.9988(0.7058)$ & $0.0272(0.0120)$ & $0.0324(0.0169)$ \\
$B A Y D I F$ & $-3.1116(0.7647)$ & $0.0139(0.0030)$ & $0.1366(0.0606)$ \\
$\gamma_{12}$ & $-0.0917(0.3355)$ & & \\
$\gamma_{13}$ & $1.0169(0.3136)$ & & \\
$\gamma_{23}$ & $-0.2269(0.3257)$ & & \\
\hline & & & \\
\hline
\end{tabular}

Table 10: Trivariate Logit Results - Coefficients of Key Variables ( Standard errors within parentheses ).

In order to test the robustness of our empirical findings, we also estimate univariate and trivariate logit models that employ an alternative operationalization of the locational differentiation measure, i.e., VIS, which measures the average relative visibility of stations within the local market from each other (as explained earlier). The results from using this alternative operationalization are consistent with those obtained using $N U M / A R E A$, except that the standard errors associated with the VIS coefficients are uniformly larger, which renders several of the associated estimates to be statistically insignificant (although they are correctly signed). Therefore, we choose to report the results obtained using $N U M / A R E A .^{21}$ We also estimate

\footnotetext{
${ }^{20}$ These results are reported in the Appendix.

${ }^{21}$ These results obtained using VIS are available from the authors.
} 


\begin{tabular}{rrrr}
\hline \hline Outcome & Intercept & SPREAD/1000 & NUM/AREA \\
\hline MODEL4 & & & \\
PRICEDIF & $-3.0583(0.8722)$ & $0.0226(0.0115)$ & $0.0174(0.0089)$ \\
HOURSDIF & $-2.5380(0.8238)$ & $0.0421(0.0137)$ & $-0.0411(0.0763)$ \\
CONVDIF & $-2.7115(0.8583)$ & $0.0129(0.0011)$ & $0.2997(0.0934)$ \\
$\gamma_{12}$ & $0.1330(0.3364)$ & & \\
$\gamma_{13}$ & $1.0716(0.3478)$ & & \\
$\gamma_{23}$ & $0.4584(0.3445)$ & & \\
MODEL5 & & & \\
PRICEDIF & $-3.0230(0.8628)$ & $0.0256(0.0121)$ & $0.0811(0.0346)$ \\
$H O U R S D I F$ & $-2.8746(0.8592)$ & $0.0425(0.0139)$ & $0.0022(0.0017)$ \\
W ASHDIF & $-0.2374(0.8104)$ & $0.0053(0.0013)$ & $-0.1192(0.0746)$ \\
$\gamma_{12}$ & $0.2391(0.3314)$ & & \\
$\gamma_{13}$ & $-0.0003(0.1973)$ & & \\
$\gamma_{23}$ & $0.6389(0.3191)$ & & \\
MODEL6 & & & \\
PRICEDIF & $-2.9786(0.8533)$ & $0.0257(0.0136)$ & $0.0489(0.0222)$ \\
HOUSDIF & $-2.5331(0.8482)$ & $0.0434(0.0141)$ & $-0.0569(0.0750)$ \\
B $D I F$ & $-3.3098(0.9574)$ & $0.0001(0.0001)$ & $0.1526(0.0839)$ \\
$\gamma_{12}$ & $-0.0664(0.4512)$ & & \\
$\gamma_{13}$ & $1.0418(0.3716)$ & & \\
$\gamma_{23}$ & $1.3582(0.3684)$ & & \\
\hline & & & \\
\hline
\end{tabular}

Table 11: Trivariate Logit Results - Coefficients of Key Variables ( Standard errors within parentheses).

linear regression models to explain the same price and service differentiation outcomes, and the results from these models are qualitatively similar to those obtained using the univariate logit models (these results are reported in the Appendix). 


\begin{tabular}{rrrr}
\hline \hline Outcome & Intercept & SPREAD/1000 & NUM/AREA \\
\hline MODEL7 & & & \\
PRICEDIF & $-2.8831(0.9199)$ & $0.0225(0.0113)$ & $0.0166(0.0086)$ \\
NOZDIF & $-0.5201(0.7251)$ & $-0.0094(0.0119)$ & $0.0036(0.0017)$ \\
CONVDIF & $-2.8002(0.8649)$ & $0.0175(0.0026)$ & $0.2951(0.0931)$ \\
$\gamma_{12}$ & $-0.5896(0.3386)$ & & \\
$\gamma_{13}$ & $1.1163(0.3472)$ & & \\
$\gamma_{23}$ & $0.2175(0.3432)$ & & \\
MODEL & & & \\
RICEDIF & $-2.8957(0.8732)$ & $0.0266(0.0127)$ & $0.0843(0.0344)$ \\
NOZDIF & $-0.6671(0.7655)$ & $-0.0094(0.0119)$ & $0.0242(0.0069)$ \\
$W A S H D I F$ & $-0.3907(0.7775)$ & $0.0118(0.0020)$ & $-0.1206(0.0735)$ \\
$\gamma_{12}$ & $-0.5423(0.3253)$ & & \\
$\gamma_{13}$ & $0.0745(0.3190)$ & & \\
$\gamma_{23}$ & $0.3060(0.3180)$ & & \\
$M O D E L 9$ & & & \\
PICEDIF & $-2.7989(0.8224)$ & $0.0240(0.0120)$ & $0.0512(0.0206)$ \\
NOZDIF & $-0.5149(1.1868)$ & $-0.0089(0.0020)$ & $0.0112(0.0016)$ \\
$B A Y D I F$ & $-3.2267(0.7246)$ & $0.0128(0.0013)$ & $0.1344(0.0804)$ \\
$\gamma_{12}$ & $-0.5734(0.3034)$ & & \\
$\gamma_{13}$ & $1.0434(0.3191)$ & & \\
$\gamma_{23}$ & $0.1556(0.3077)$ & & \\
\hline
\end{tabular}

Table 12: Trivariate Logit Results - Coefficients of Key Variables ( Standard errors within parentheses).

\begin{tabular}{rrrr}
\hline \hline Outcome & Intercept & SPREAD/1000 & NUM/AREA \\
\hline MODEL10 & & & \\
PRICEDIF & $-2.8720(0.9591)$ & $0.0231(0.0112)$ & $0.0307(0.0103)$ \\
$P A Y D I F$ & $-0.6749(0.7712)$ & $-0.0046(0.0124)$ & $0.0864(0.0360)$ \\
CONVDIF & $-2.8468(0.8667)$ & $0.0174(0.0027)$ & $0.2883(0.0930)$ \\
$\gamma_{12}$ & $-0.7323(0.3503)$ & & \\
$\gamma_{13}$ & $1.1431(0.3494)$ & & \\
$\gamma_{23}$ & $0.3507(0.3476)$ & & \\
MODEL11 & & & \\
PRICEDIF & $-2.8236(0.8959)$ & $0.0276(0.0128)$ & $0.0941(0.0456)$ \\
$P A Y D I F$ & $-0.3905(0.7993)$ & $-0.0014(0.0132)$ & $0.0872(0.0352)$ \\
WASHDIF & $-0.0312(0.1862)$ & $0.0110(0.0095)$ & $-0.1041(0.0733)$ \\
$\gamma_{12}$ & $-0.6583(0.3399)$ & & \\
$\gamma_{13}$ & $-0.0729(0.3054)$ & & \\
$\gamma_{23}$ & $-0.7429(0.3219)$ & & \\
$M O D E L 12$ & & & \\
PRICEDIF & $-2.8133(0.8648)$ & $0.0248(0.0120)$ & $0.0651(0.0268)$ \\
$P A Y D I F$ & $-0.7092(0.7619)$ & $-0.0030(0.0125)$ & $0.1093(0.0544)$ \\
$B A Y D I F$ & $-3.1170(0.9107)$ & $0.0124(0.0028)$ & $0.1385(0.0807)$ \\
$\gamma_{12}$ & $-0.6126(0.3447)$ & & \\
$\gamma_{13}$ & $1.0017(0.3371)$ & & \\
$\gamma_{23}$ & $-0.1476(0.3654)$ & &
\end{tabular}

Table 13: Trivariate Logit Results - Coefficients of Key Variables ( Standard errors within parentheses). 


\begin{tabular}{rrrr}
\hline \hline Outcome & Intercept & SPREAD/1000 & NUM/AREA \\
\hline MODEL13 & & & \\
PRICEDIF & $-3.0008(1.1126)$ & $0.0215(0.0113)$ & $0.0091(0.0023)$ \\
$F U L L D I F$ & $-3.9628(1.0387)$ & $0.0288(0.0136)$ & $0.0744(0.0086)$ \\
CONVDIF & $-2.6255(0.9257)$ & $0.0066(0.0044)$ & $0.2683(0.0996)$ \\
$\gamma_{12}$ & $0.4760(0.4094)$ & & \\
$\gamma_{13}$ & $0.9189(0.4001)$ & & \\
$\gamma_{23}$ & $1.9451(0.4171)$ & & \\
MODEL14 & & & \\
PRICEDIF & $-2.9373(0.8304)$ & $0.0227(0.0108)$ & $0.0516(0.0255)$ \\
$F U L L D I F$ & $-3.7034(0.9685)$ & $0.0311(0.0132)$ & $0.1676(0.0779)$ \\
$W A S H D I F$ & $-3.1544(1.0081)$ & $-0.0029(0.0148)$ & $0.0755(0.0410)$ \\
$\gamma_{12}$ & $0.4205(0.4129)$ & & \\
$\gamma_{13}$ & $0.8404(0.3749)$ & & \\
$\gamma_{23}$ & $2.5170(0.4598)$ & & \\
MODEL 15 & & & \\
$P R I C E D I F$ & $-2.9376(0.8508)$ & $0.0231(0.0112)$ & $0.0405(0.0162)$ \\
$F U L L D I F$ & $-3.9521(1.0812)$ & $0.0328(0.0148)$ & $0.1291(0.0645)$ \\
$B A Y D I F$ & $-3.1544(1.0081)$ & $-0.0029(0.0148)$ & $0.0755(0.0310)$ \\
$\gamma_{12}$ & $0.4205(0.4129)$ & & \\
$\gamma_{13}$ & $0.8404(0.3749)$ & & \\
$\gamma_{23}$ & $2.5170(0.4598)$ & & \\
\hline & & &
\end{tabular}

Table 14: Trivariate Logit Results - Coefficients of Key Variables ( Standard errors within parentheses). 


\section{Conclusion}

In many markets, firms compete both in their product design as well as in their price choices. The literature on imperfect competition has examined the impact of horizontal differences among consumers (as in models of spatial competition), as well as differences in consumer valuations

for product quality (as in models of vertical differentiation). A variety of retail markets are characterized by the presence of consumer heterogeneity on both of these dimensions. Retail gasoline markets present a nice empirical environment to examine the interaction between these dimensions and their effect on the competitive product design and price choices of firms. In markets where the locational (horizontal) differentiation between retailers is strong relative to the diversity in consumers' valuations for quality, retailers adopt similar strategies. In contrast, markets with low locational differentiation and substantial vertical heterogeneity drive retailers towards differentiated behavior.

Using data from the retail gasoline market in Saint Louis, we are able to show that the degree of local competitive intensity and the dispersion in consumer incomes are sufficient to explain the variations in the product and pricing choices of competing firms. We show that the standard deviation of price in a market is positively related to the standard deviation of per-capita income in that market. In addition, the standard deviation of important quality characteristics of stations (such as brand name, full service, pay at pump etc.) in a market is also positively related to the standard deviation of income. The empirical study also finds that the standard deviation of price and service characteristics are higher for clustered gas stations which face more direct competition from one another than for stations in less clustered markets. Thus our study is able to establish how the product and pricing decisions of competitive firms are jointly affected by some fundamental characteristics of local markets. 


\section{References}

Anderson, S.P., de Palma, A., Thisse, J.F. (1996). Discrete Choice Theory of Product Differentiation, The MIT Press.

Ashford, J.R., Sowden, R.R. (1970). Multivariate Probit Analysis, Biometrics, 26, 3, 535-546.

Bresnahan, T.F., Reiss, P.C. (1991). Entry and Competition in Concentrated Markets, Journal of Political Economy, 99, 5, 977-1009.

Chan, T.Y., Padmanabhan, V., Seetharaman, P.B. (2007). An Econometric Model of Location and Pricing in the Gasoline Market, Journal of Marketing Research, 44, 4, 622-635.

D'Aspremont, C., Gabszewicz, J.J., Thisse, J.F. (1979). On Hotelling's 'Stability in Competition', Econometrica, 47, 5, 1145-1150.

Dasgupta, P., Maskin, E. (1986). The Existence of Equilibrium in Discontinuous Economic Games, The Review of Economic Studies, 53, 1, 1-26.

Davis, P. (2005). The Effect of Local Competition on Retail Prices: The US Motion Picture Exhibition Market, Journal of Law and Economics, 48, 2, 677-708.

Desai, P. (2001). Quality Segmentation in Spatial Markets: When does cannibalization affect product line design, Marketing Science, 20, 265283.

Draganska, M., Jain, D.C. (2006). Consumer Preferences and Product-Line Pricing Strategies: An Empirical Analysis, Marketing Science, forthcoming.

Grizzle, J.E. (1971). Multivariate Logit Analysis, Biometrics, 27, 4, 1057-1062.

Hill, M.S. (1985). Patterns of Time Use, in Time, Goods and Well-Being, eds. F. Thomas Juster and Frank Stafford, Survey Research Center, University of Michigan, 133-176.

Hotelling, H. (1929). Stability in Competition, Economic Journal, 39, 153, 41-57.

Iyer G. (1998). Coordinating Channels Under Price and Non-price Competition, Marketing Science, 17, 4, 338-355.

Niraj, R., Padmanabhan V., Seetharaman P.B. (2008), A Cross-Category Model of Households Incidence and Quantity Decisions, forthcoming, Marketing Science.

Maurizi A. and T. Kelly (1978). Prices and Consumer Information: The Benefits of Posting Retail Gasoline Prices, Washington DC: American Enterprise Institute.

Mazzeo, M.J. (2002). Product Choice and Oligopoly Market Structure, The RAND Journal of Economics, 33, 2, 221-242.

Moorthy, K.S. (1988). Product and Price Competition in a Duopoly, Marketing Science, 7, 2, 141-168.

Mussa, M., Rosen, S. (1978). Monopoly and Product Quality, Journal of Economic Theory, $18,2,301-317$. 
Neven, D., Thisse, J.F. (1990). On Quality and Variety Competition, in Economic DecisionMaking: Games, Econometrics and Optimization, Chapter 9, eds. J.J. Gabszewicz, J.F. Richard and L.A. Wolsey, North Holland.

Perloff J. and S. Salop (1985) "Equilibrium with Product Differentiation" Review of Economic Studies, 52, 107-20.

Pinkse, J., Slade, M.E., Brett, C. (2002). Spatial Price Competition: A Semiparametric Approach, Econometrica, 70, 3, 1111-1153.

Png, I.P.L., Reitman, D. (1994). Service Time Competition, The RAND Journal of Economics, $25,4,619-634$.

Rochet, J.C., and L.A. Stole (2002). Nonlinear Pricing with Random Participation, Review of Economic Studies, 69, 277-311.

Schmidt-Mohr, U. and J. Miguel Villas-Boas (2008). Competitive Product Lines with Quality Constraints, Quantitative Marketing and Economics, 6, 1, 1-16.

Seim, K. (2004). An Empirical Model of Firm Entry with Endogenous Product-Type Choices, Working paper, Graduate School of Business, Stanford University.

Shaked, A., Sutton, J. (1982). Relaxing Price Competition through Product Differentiation, The Review of Economic Studies, 49, 1, 3-13.

Shepard, A. (1991). Price Discrimination and Retail Configuration, The Journal of Political Economy, 99, 1, 30-53.

Slade, M.E. (1986). Exogeneity Tests of Market Boundaries Applied to Petroleum Products, The Journal of Industrial Economics, 34, 3, 291-303.

Slade, M.E. (1992). Vancouver Gasoline Price Wars: An Empirical Exercise in Uncovering Supergame Strategies, The Review of Economic Studies, 59, 2, 257-276. 


\section{Appendix}

\subsection{Symmetric Equilibrium}

The second-order conditions $\frac{\partial^{2} \pi_{j}(\cdot)}{\partial q_{j}^{2}}<0$ imply that $t>\frac{2 v \theta_{l}}{9(v+1))}$. In this range, the reduced-form profit functions are strictly quasi-concave and continuous in $q_{j}$. From Dasgupta and Maskin (1986), the strict quasi-concavity and the continuity of the reduced-form profit functions are sufficient for the existence of a pure-strategy equilibrium. Consider the range $t>\frac{2 v \theta_{l}}{9(v+1))}$. Simultaneously solving the reaction functions results in the unique symmetric equilibrium reported in the paper.

\subsection{Asymmetric Equilibrium}

Here we solve for the asymmetric equilibrium of the model, which involves one firm (say, Firm 1) offering higher quality and price and selling to the higher valuation segment, while the other firm offers lower quality and price and sells to the lower valuation segment. Consider the individual rationality and the incentive compatibility constraints for this asymmetric equilibrium shown in equations (6)-(9). First, it can be noted that given that each firm is selling to one complete segment of consumers, if the incentive compatibility constraint for a firm is binding, then the individual rationality constraint for that firm should be slack. Similarly, if the individual rationality constraint for a firm is binding, the incentive compatibility constraint for that firm must be slack.

Consider now the case when equations (7) and (8) are the binding constraints, while equations (6) and (9) are slack. From equation (7), we have $p_{2}=\theta_{l} q_{2}-t \theta_{l}$ and $p_{1}=p_{2}+\theta_{h}\left(q_{1}-q_{2}\right)-t \theta_{h}$. The profit functions of the two firms are $\pi_{1}=\frac{p_{1}}{2}-\frac{q_{1}^{2}}{2}$ and $\pi_{2}=\frac{p_{2}}{2}-\frac{q_{2}^{2}}{2}$, from which the equilibrium quality choices are $q_{1}^{*}=\frac{\theta_{h}}{2}=\frac{v \theta_{l}}{2}$ and $q_{2}^{*}=\frac{\theta_{l}}{2}$. Therefore, the equilibrium prices are $p_{1}^{*}=\frac{\theta_{l}^{2}}{2}[1+v(v-1)]-t \theta_{l}(v+1)$ and $p_{2}^{*}=\frac{\theta_{l}^{2}}{2}-t \theta_{l}$. To identify the condition for the existence of this equilibrium, we use the slack constraints. Specifically, from equation (9) we have that $t<\frac{\theta_{l}}{2} \frac{(v-1)^{2}}{v+1}$. For the equilibrium quality and price levels, the inequality in equation (6) is strictly satisfied. Also we require that the equilibrium prices be positive, which implies that $p_{2}^{*}>0$ which implies that $t<\frac{\theta_{l}}{2}$.

We now have to check to ensure that there is no profitable deviation from the equilibrium strategy for either firm. Let us first look at possible deviations for Firm 2 (the low quality, low price firm), given that Firm 1 is at the equilibrium strategy. Consider a general deviation in which Firm 2 serves $0<y_{2 d}<1$ high type consumers closest to it, and some $0<x_{2 d}<1$ low type consumers. Then $y_{2 d}$ is determined by $\theta_{h} q_{2 d}-p_{2 d}-t \theta_{h} y_{2 d}-\left[\theta_{h} q_{1}^{*}-p_{1}^{*}-t \theta_{h}\left(1-y_{2 d}\right)\right]=0$ and $x_{2 d}$ is given by $\theta_{l} q-p-t \theta_{l} x_{2 d}=0$. The deviation profits are $\pi_{2 d}=p_{2 d}\left(\frac{y_{2 d}+x_{2 d}}{2}\right)-\frac{q_{2 d}^{2}}{2}$. We solve first for the optimal $p_{2 d}$ and then substitute it in the profits to then solve for the optimal $q_{2 d}$. The second-order condition for a maximum with respect to $q_{2 d}$ implies $t>\frac{9 v}{8(1+2 v)}$, otherwise $\pi_{2 d}$ will be at a minimum of zero. Comparing $\pi_{2 d}$ to the equilibrium profits, it can be shown that when $t>\frac{9 v}{8(1+2 v)}$, the equilibrium profits are always higher and, therefore, this deviation cannot be profitable. Next, consider a deviation in which Firm 2 abandons the low type segment and competes only in the high type segment. Again, if $0<y_{2 d}<$ 1 , high type consumers along the line closest to it buy from Firm 2, then $y_{2 d}$ is given by 
$\theta_{h} q_{2 d}-p_{2 d}-t \theta_{h} y_{2 d}-\left[\theta_{h} q_{1}^{*}-p_{1}^{*}-t \theta_{h}\left(1-y_{2 d}\right)\right]=0$. The profit for Firm 2 is $\pi_{2 d}=\frac{p_{2 d} y_{2 d}}{2}-\frac{q_{2 d}^{2}}{2}$. The second-order condition for a maximum is $t>\frac{v}{8}$, and in this range the deviation profits are greater than the equilibrium profits. But for $t<\frac{v}{8}$ the equilibrium profits are greater than the deviation profits. Finally, there can be a possible deviation in which Firm 2 sells to all the consumers in the market and an analysis similar to that above shows that this deviation is also not possible.

Next we check for possible deviations by Firm 1, i.e., the high quality firm (given that Firm 2 is adopting the equilibrium strategy). Consider a general deviation in which Firm 1 serves $0<x_{1 d}<1$ low type consumers closest to it and some $0<y_{1 d}<1$. Then $x_{1 d}$ is determined by $\theta_{l} q_{1 d}-t \theta_{l} x_{1 d}-p_{1 d}-\left(\theta_{l} s_{2}^{*}-t \theta_{l}\left(1-x_{1 d}\right)-p_{2}^{*}\right)=0$ and $y_{1 d}$ is given by $\theta_{h} q_{1 d}-t \theta_{h} y_{1 d}-p_{1 d}=0$. Calculations can show that the deviation profits for this case will be lower than the equilibrium profits. Finally, we must check the possible deviation for Firm 1 in which it sells to the entire market. We can show that this deviation is not profitable if $t<\frac{v^{2}-2 v-2}{4(v-3)}$.

Next, for $r=0$ and $\theta_{l}=1$ we need that $t<\frac{v^{2}-2 v+2}{4(v+1)}$ for Firm 1's equilibrium profit to be positive, and $t<\frac{1}{4}$ for Firm 2's equilibrium profit to be positive. Collecting all the constraints reported above and identifying the binding constraints we have that the asymmetric equilibrium exists when $t<\min \left\{\frac{(v-1)^{2}}{2(v+1)}, \frac{v^{2}-2 v-2}{4(v-3)}, \frac{v^{2}-2 v+2}{4(v+1)}, \frac{1}{4}\right\}$.

The asymmetric equilibrium for the case when equations (6) and (9) are the binding constraints can be solved in a similar fashion.

\subsection{Coefficients of Control Variables from the Trivariate Logit Model}

\begin{tabular}{rrrrr}
\hline \hline Outcome & TRAFFICDIF & FREEWAYMEAN & GINIOPER & \multicolumn{1}{c}{ GINIBLDG } \\
\hline MODEL1 & & & \\
PRICEDIF & $0.7643(0.3253)$ & $0.2439(0.5364)$ & $1.2534(0.6142)$ & $0.7199(0.3012)$ \\
BRANDDIF & $0.2201(0.1035)$ & $0.0131(0.0690)$ & $-1.1586(1.1162)$ & $0.8677(0.4607)$ \\
CONVDIF & $-0.2662(0.3307)$ & $0.3793(0.5649)$ & $1.7224(0.8221)$ & $-0.3248(1.3872)$ \\
MODEL & & & & \\
PRICEDIF & $0.6976(0.3129)$ & $0.3411(0.5356)$ & $1.6411(0.6669)$ & $0.6467(0.2489)$ \\
BRANDDIF & $0.2691(0.1279)$ & $-0.0568(0.6580)$ & $-1.4472(1.0903)$ & $0.9266(0.5175)$ \\
WASHDIF & $0.2966(0.1945)$ & $-0.7188(0.5313)$ & $-0.1458(1.1818)$ & $1.1409(0.5571)$ \\
MODEL3 & & & \\
PRICEDIF & $0.6960(0.2998)$ & $0.3086(0.5438)$ & $1.3150(0.6701)$ & $0.2794(0.1174)$ \\
BRANDDIF & $0.2680(0.1323)$ & $-0.0474(0.3049)$ & $-1.3785(1.0543)$ & $0.9921(0.5179)$ \\
BAYDIF & $0.0273(0.0912)$ & $0.1287(0.4490)$ & $1.4615(0.7944)$ & $1.8921(0.9121)$ \\
\hline & & & &
\end{tabular}

Table 15: Trivariate Logit Results - Coefficients of Control Variables ( Standard errors within parentheses ). 


\begin{tabular}{rrrrr}
\hline \hline Outcome & TRAFFICDIF & FREEWAYMEAN & GINIOPER & GINIBLDG \\
\hline MODEL4 & & & & \\
PRICEDIF & $0.7575(0.3251)$ & $0.2540(0.5509)$ & $1.2215(0.6850)$ & $0.6953(0.2593)$ \\
HOURSDIF & $0.3142(0.1111)$ & $-0.3345(0.5263)$ & $0.5592(0.2568)$ & $1.2059(0.6076)$ \\
CONVDIF & $-0.3425(0.3307)$ & $0.4108(0.5649)$ & $1.9027(0.8221)$ & $-0.6246(1.3872)$ \\
MODEL5 & & & & \\
PRICEDIF & $0.6754(0.3149)$ & $0.3528(0.5702)$ & $1.6492(0.6499)$ & $0.5637(0.2394)$ \\
HOURSDIF & $0.2402(0.1119)$ & $-0.1898(0.5295)$ & $0.7697(0.4330)$ & $1.0022(0.5069)$ \\
WASHDIF & $0.2611(0.1980)$ & $-0.6928(0.5281)$ & $-0.2451(1.4812)$ & $0.9932(0.3618)$ \\
MODEL6 & & & \\
PRICEDIF & $0.6941(0.3302)$ & $0.3050(0.5435)$ & $1.3498(0.6042)$ & $0.2681(0.1603)$ \\
HOURSDIF & $0.3059(0.1504)$ & $-0.3582(0.5788)$ & $0.3379(0.2374)$ & $0.7755(0.3435)$ \\
BAYDIF & $-0.0794(0.4471)$ & $0.2389(0.6163)$ & $1.4454(0.7861)$ & $1.5958(0.8161)$ \\
\hline
\end{tabular}

Table 16: Trivariate Logit Results - Coefficients of Control Variables ( Standard errors within parentheses ).

\begin{tabular}{rrcrr}
\hline \hline Outcome & TRAFFICDIF & FREEWAYMEAN & GINIOPER & GINIBLDG \\
\hline MODEL7 & & & & \\
PRICEDIF & $0.8184(0.3304)$ & $0.2554(0.5646)$ & $1.3682(0.6327)$ & $0.8508(0.3395)$ \\
NOZDIF & $0.3685(0.2032)$ & $0.0780(0.4913)$ & $0.9262(0.4677)$ & $0.8736(0.4599)$ \\
CONVDIF & $-0.3292(0.3306)$ & $0.3729(0.5679)$ & $1.9092(0.8971)$ & $-0.5442(1.3566)$ \\
MODEL8 & & & & \\
PRICEDIF & $0.7307(0.3182)$ & $0.3627(0.5518)$ & $1.8209(0.6584)$ & $0.7135(0.2373)$ \\
NOZDIF & $0.3332(0.3026)$ & $0.1478(0.4895)$ & $1.0230(0.4805)$ & $0.7735(0.3374)$ \\
WASHDIF & $0.2706(0.1008)$ & $-0.7291(0.5128)$ & $-0.2106(0.8733)$ & $1.0792(0.5233)$ \\
MODEL9 & & & & \\
PRICEDIF & $0.7381(0.2965)$ & $0.3226(0.5299)$ & $1.4765(0.6806)$ & $0.3643(0.1116)$ \\
NOZDIF & $0.3538(0.3012)$ & $0.0913(0.5671)$ & $0.9596(0.4029)$ & $0.8054(0.3774)$ \\
BAYDIF & $-0.0003(0.3786)$ & $0.1279(0.2256)$ & $1.5019(0.7430)$ & $1.8085(0.8856)$ \\
\hline
\end{tabular}

Table 17: Trivariate Logit Results - Coefficients of Control Variables ( Standard errors within parentheses ).

\begin{tabular}{rrrrr}
\hline \hline Outcome & TRAFFICDIF & FREEWAYMEAN & GINIOPER & \multicolumn{1}{c}{ GINIBLDG } \\
\hline MODEL10 & & & & \\
PRICEDIF & $0.8957(0.3353)$ & $0.1601(0.6327)$ & $1.2718(0.6069)$ & $0.8077(0.3970)$ \\
PAYDIF & $0.7762(0.3162)$ & $-0.5148(0.5227)$ & $0.2065(1.2250)$ & $0.5127(0.2856)$ \\
CONVDIF & $-0.3715(0.3334)$ & $0.4174(0.5653)$ & $1.9410(0.8474)$ & $-0.5377(1.2925)$ \\
MODEL11 & & & \\
PRICEDIF & $0.8085(0.3244)$ & $0.2531(0.5794)$ & $1.7359(0.7509)$ & $0.7096(0.3092)$ \\
PAYDIF & $0.8257(0.3207)$ & $-0.6286(0.5263)$ & $0.3227(1.1305)$ & $0.6956(0.3334)$ \\
WASHDIF & $0.4319(0.3044)$ & $-0.8217(0.4518)$ & $-0.0839(1.1957)$ & $1.2426(0.6063)$ \\
MODEL12 & & & & \\
PRICEDIF & $0.7951(0.3338)$ & $0.2434(0.5689)$ & $1.3984(0.6657)$ & $0.3232(0.1173)$ \\
PAYDIF & $0.7500(0.3122)$ & $-0.4819(0.5185)$ & $0.3862(1.2359)$ & $0.5248(0.2637)$ \\
BAYDIF & $0.0379(0.4001)$ & $0.1153(0.5544)$ & $1.5503(0.7405)$ & $1.8534(0.9678)$ \\
\hline
\end{tabular}

Table 18: Trivariate Logit Results - Coefficients of Control Variables ( Standard errors within parentheses). 


\begin{tabular}{rrrrr}
\hline \hline Outcome & TRAFFICDIF & FREEWAYMEAN & GINIOPER & GINIBLDG \\
\hline MODEL13 & & & \\
PRICEDIF & $0.7584(0.3300)$ & $0.3027(0.5635)$ & $1.2424(0.6134)$ & $0.5988(0.2542)$ \\
FULLDIF & $0.1160(0.4032)$ & $-0.6903(0.6516)$ & $-0.0761(1.6407)$ & $1.8850(0.9218)$ \\
CONVDIF & $-0.3474(0.3536)$ & $0.6340(0.6462)$ & $1.9754(0.9597)$ & $-1.0756(1.3333)$ \\
MODEL14 & & & & \\
PRICEDIF & $0.6942(0.3163)$ & $0.4159(0.5399)$ & $1.5745(0.7635)$ & $0.4261(0.2299)$ \\
FULLDIF & $-0.0332(0.3163)$ & $-0.4006(0.5839)$ & $0.7338(0.4394)$ & $1.4171(0.7854)$ \\
WASHDIF & $0.2958(0.2881)$ & $-0.7049(0.5130)$ & $-0.1568(0.9773)$ & $1.1027(0.5773)$ \\
MODEL15 & & & \\
PRICEDIF & $0.6924(0.3197)$ & $0.3533(0.5415)$ & $1.3488(0.6015)$ & $0.2220(0.1795)$ \\
FULLDIF & $-0.0358(0.3145)$ & $-0.6405(0.6677)$ & $-0.0669(0.6982)$ & $0.6895(0.2893)$ \\
BAYDIF & $0.0289(0.0573)$ & $0.4248(0.6428)$ & $1.5493(0.7848)$ & $1.5699(0.7980)$ \\
\hline
\end{tabular}

Table 19: Trivariate Logit Results - Coefficients of Control Variables ( Standard errors within parentheses). 


\subsection{Results from the Linear Regression Model}

\begin{tabular}{rrrr}
\hline \hline Outcome & Intercept & SPREAD/1000 & NUM/AREA \\
\hline PRICEDIF & $-6.2645(6.9604)$ & $0.3038(0.1235)$ & $0.5688(0.2378)$ \\
BRANDDIF & $0.2226(0.0937)$ & $0.0024(0.0010)$ & $0.0047(0.0010)$ \\
HOURSDIF & $-0.0060(0.1017)$ & $0.0059(0.0016)$ & $-0.0041(0.0093)$ \\
NOZDIF & $1.0235(0.2704)$ & $-0.0041(0.0043)$ & $-0.0336(0.0258)$ \\
PAYDIF & $0.2849(0.0977)$ & $-0.0010(0.0015)$ & $0.0021(0.0009)$ \\
FULLDIF & $-0.1196(0.0856)$ & $0.0047(0.0014)$ & $0.0185(0.0082)$ \\
CONVDIF & $-0.0260(0.0963)$ & $0.0030(0.0015)$ & $0.0341(0.0092)$ \\
WASHDIF & $0.2931(0.1008)$ & $0.0021(0.0010)$ & $-0.0178(0.0096)$ \\
BAYDIF & $-0.0630(0.0971)$ & $0.0026(0.0012)$ & $0.0145(0.0072)$ \\
\hline
\end{tabular}

Table 20: Linear Regression Results - Coefficients of Key Variables ( Standard errors within parentheses ).

\begin{tabular}{rrrrr}
\hline \hline Outcome & TRAFFICDIF & FREEWAYMEAN & GINIOPER & GINIBLDG \\
\hline PRICEDIF & $7.9675(3.1689)$ & $3.7470(5.0122)$ & $12.3002(5.3738)$ & $6.2644(2.6624)$ \\
BRANDDIF & $-0.0029(0.0379)$ & $-0.0107(0.0649)$ & $-0.0349(0.1369)$ & $0.2547(0.1245)$ \\
HOURSDIF & $0.0524(0.0293)$ & $-0.0463(0.0679)$ & $0.0624(0.0330)$ & $0.1768(0.0807)$ \\
NOZDIF & $0.1589(0.1088)$ & $-0.2090(0.1872)$ & $0.3475(0.1950)$ & $0.5723(0.2164)$ \\
PAYDIF & $0.0764(0.0393)$ & $-0.1318(0.0676)$ & $0.1259(0.0431)$ & $0.2073(0.1008)$ \\
FULLDIF & $0.0096(0.0345)$ & $-0.0264(0.0593)$ & $0.1248(0.0555)$ & $0.0428(0.0222)$ \\
CONVDIF & $-0.0285(0.0385)$ & $0.0791(0.0664)$ & $0.3306(0.1401)$ & $-0.1914(0.1476)$ \\
WASHDIF & $0.0399(0.0406)$ & $-0.1326(0.0698)$ & $-0.0205(0.1518)$ & $0.0958(0.0491)$ \\
BAYDIF & $0.0163(0.0188)$ & $0.0310(0.0671)$ & $0.2816(0.1410)$ & $0.0658(0.0493)$ \\
\hline
\end{tabular}

Table 21: Linear Regression Results - Coefficients of Control Variables ( Standard errors within parentheses). 